\title{
Differential Effects of Chronic Antipsychotic Drug Treatment on Extracellular Glutamate and Dopamine Concentrations
}

\author{
Bryan K. Yamamoto and Mary Ann Cooperman \\ Department of Psychiatry, School of Medicine, Case Western Reserve University, Cleveland, Ohio 44106-5000
}

\begin{abstract}
Typical and atypical antipsychotic drugs have been reported to affect basal dopaminergic activity differentially in nigrostriatal and limbic structures after acute and chronic administration in animals. In addition, glutamate has been implicated in the pathophysiology of schizophrenia. The purpose of this study was to examine basal and locally stimulated glutamate and dopamine efflux in the caudate, nucleus accumbens, and medial prefrontal cortex using in vivo microdialysis after chronic clozapine and haloperidol treatment. Basal extracellular concentrations of dopamine in the caudate and nucleus accumbens were not different between the drug treatment groups; however, dopamine concentrations were higher in the medial prefrontal cortex after chronic clozapine treatment. Depolarization-induced dopamine release with $80 \mathrm{~mm} \mathrm{~K}^{+}$in all three brain regions was attenuated by haloperidol treatment. In contrast, basal concentrations of extracellular glutamate were markedly higher in the caudate and modestly increased in the nucleus accumbens but not in the prefrontal cortex after chronic haloperidol. Chronic clozapine treatment did not have an effect in any of the brain regions examined. $\mathrm{K}^{+}$-stimulated glutamate efflux was unaffected by haloperidol or clozapine in the caudate or prefrontal cortex; however, stimulated glutamate release in the nucleus accumbens was enhanced by clozapine. These data are suggestive of a depolarization inactivation of dopamine nerve terminals in striatum and cortex as revealed by an attenuation of local $\mathrm{K}^{+}$-induced stimulation of dopamine efflux. These results also provide new evidence for a role of glutamate in discriminating the neurochemical effects of chronic treatment with antipsychotic drugs.
\end{abstract}

[Key words: antipsychotics, glutamate, dopamine, cortex, striatum, microdialysis]

Chronic administration of antipsychotic drugs is a mainstay therapy for the treatment of psychoses. Although the acute effects of these agents with regard to their dopamine antagonist properties have been well characterized (Creese et al., 1976; Seeman et al., 1976; Meltzer et al., 1989; Stockmeier et al., 1993), results regarding their brain region-selective effects on mesostriatal and mesolimbic dopamine systems following chronic treatment are inconsistent. Elcctrophysiological studies

\footnotetext{
Received July 19, 1993; revised Nov. 24, 1993; accepted Dec. 31, 1993.

This work was supported in part by USPHS Grant NS24814 and the Scottish Rite Schizophrenia Research Program.

Correspondence should be addressed to Bryan K. Yamamoto, Ph.D., Department of Psychiatry, University Hospitals of Cleveland, Hanna Pavilion, 2040 Abington Road, Cleveland, Ohio 44106-5000.

Copyright (C) 1994 Society for Neuroscience $0270-6474 / 94 / 144159-08 \$ 05.00 / 0$
}

have demonstrated that repeated treatment with typical antipsychotic drugs such as haloperidol produces a decrease in the number of spontaneously active dopamine cells in the substantia nigra pars compacta and the ventral tegmental area. This is in contrast to the atypical antipsychotic drug clozapine, which only reduces the number of spontaneously firing dopamine neurons in the ventral tegmental area (Chiodo and Bunney, 1983, 1985; White and Wang, 1983a,b; Grace and Bunney, 1986). Therefore, the therapeutic efficacy of antipsychotic drugs is hypothesized to be due to the depolarization inactivation of the A10 mesolimbic dopamine system whereas the side-effect liability of chronic treatment with typical neuroleptics such as haloperidol is the result of a persistent depression of neuronal firing in the A9 nigrostriatal system.

Subsequent studies have attempted to relate these electrophysiological results to functional neurochemical measures of extracellular dopamine concentrations in forebrain dopamine terminal regions such as the caudate-putamen, nucleus accumbens, and prefrontal cortex. Extracellular dopamine concentrations measured in vivo by microdialysis or voltammetry in the caudate-putamen following chronic haloperidol administration are either decreased (Blaha and Lane, 1987; Lane and Blaha, 1987; Hernandez and Hoebel, 1989; Ichikawa and Meltzer, 1990a,b, 1991, 1992; See, 1991; Yamada et al., 1991), increased (Zhang et al., 1989), or unchanged (See, 1991; See et al., 1992; Weidemann et al., 1992). Of the fewer studies that have examined brain nuclei other than the caudate following chronic haloperidol, basal extracellular dopamine was either decreased or unaffected in the nucleus accumbens (DeBelleroche and Neal, 1982; Blaha and Lane, 1987; Lane and Blaha, 1987; Ichikawa and Meltzer, 1990a,b, 1991, 1992; See et al., 1992) and prefrontal cortex (Hernandez and Hoebel, 1989; Chen et al., 1992). Similar studies of chronic clozapine administration have also yielded mixed findings. Although most investigators report no changes in caudate dopamine content after $21 \mathrm{~d}$ of chronic treatment with clozapine (Blaha and Lane, 1987; Ichikawa and Meltzer, 1990a, 1991; Chen et al., 1991; Chai and Meltzer, 1992), dopamine concentrations in the nucleus accumbens and medial prefrontal cortex are either diminished (Blaha and Lane, 1987; Ichikawa and Meltzer, 1990a, 1991; Chen et al., 1991) or unchanged (Chen ct al., 1992).

Since all antipsychotic drugs are dopamine antagonists to varying degrees, previous studies have focused on forebrain dopamine systems. There is increasing evidence, however, of an interaction between dopamine and the excitatory amino acid neurotransmitter glutamate. In particular, there is a substantial amount of anatomical and neurochemical evidence that dopamine can modulate corticostriatal glutamate efflux via the D-2 receptor (Garau et al., 1978; Schwarcz et al., 1978; Mitchell and 
Doggett, 1980; Rowlands and Roberts, 1980; Theodorou et al,, 1981; Nieoullon et al., 1982; Filloux et al., 1988; Kerkerian and Nieoullon, 1988; Maura et al., 1988, 1989; Yamamoto and Davy, 1992). Furthermore, others have reported a dysfunction of the glutamatergic system in schizophrenia (Kim et al., 1980, 1983; Nishikawa et al., 1983; Carlsson and Carlsson, 1990; Sherman et al., 1991a,b). More recent studies have shown that acute administration of antipsychotic drugs selectively increases extracellular concentrations of glutamate in the prefrontal cortex (Pehek et al., 1992; Daly and Moghaddam, 1993). Therefore, the putative glutamatergic effects of chronic antipsychotic treatment may be an important component of the pharmacological profile of these drugs and may be dependent, in part, upon their antidopaminergic activity.

As noted above, in vivo pharmacological and neurochemical studies have focused on spontaneous or basal concentrations of dopamine in the caudate-putamen and/or nucleus accumbens, with much less attention directed to the prefrontal cortex. Collectively, these studies have yielded varied results. However, in light of the aforementioned ability of antipsychotic drugs to produce depolarization inactivation of midbrain dopamine neurons that project to forebrain terminal regions, it is possible that stimulated or local depolarization-induced release of dopamine and glutamate within nerve terminal areas may more consistently differentiate the possible brain region selective effects of chronic antipsychotic drug treatment. No singular in vivo study to date has systematically compared and contrasted the effects of chronic treatment of haloperidol and clozapine on basal and depolarization-induced dopamine and glutamate efflux in striatal and cortical brain regions.

Therefore, the purpose of this study was to examine in vivo whether chronic treatment with the atypical antipsychotic drug clozapine, compared to haloperidol, differentially affects basal and/or depolarization-induced dopamine and glutamate efflux measured by microdialysis in the caudate, nucleus accumbens, and prefrontal cortex of the awake-behaving rat.

\section{Materials and Methods}

Animals. Male Sprague-Dawley rats weighing between 190 and $220 \mathrm{gm}$ were purchased from Zivic Miller Laboratory (Alison Park, PA) and used in all experiments. Animals were housed two per cage in a temperature controlled room $\left(23^{\circ} \mathrm{C}\right)$ with a $12 \mathrm{hr} / 12 \mathrm{hr}$ light/dark cycle. Food and water were available ad libitum.

Drug administration. Haloperidol $(0.5 \mathrm{mg} / \mathrm{kg})$, clozapine $(20 \mathrm{mg} / \mathrm{kg})$, or $0.1 \mathrm{M}$ tartaric acid vehicle $(1 \mathrm{ml} / \mathrm{kg})$ was administered intraperitoneally for 21 consecutive days. These doses and the regimen were based on previous studies comparing the differential in vivo electrophysiological and receptor binding characteristic of these drugs (Chiodo and Bunney, 1983; White and Wang, 1983; Stockmeier et al., 1993). All drug solutions were prepared daily and adjusted to $\mathrm{pH} 5.7-6.0$ with $\mathrm{NaOH}$. Rats were weighed every other day and injected with the drugs between 0800 and 1100 . After $21 \mathrm{~d}$ of treatment, all rats weighed between 320 and $360 \mathrm{gm}$.

Surgery. Three days prior to the termination of the $21 \mathrm{~d}$ chronic treatment, rats were anesthetized with a combination of chloral hydrate $(150 \mathrm{mg} / \mathrm{kg}$, i.p.) and ketamine $(50 \mathrm{mg} / \mathrm{kg}$, i.p.). The skull was exposed and a $1 \mathrm{~mm}$ hole was drilled through the bone above the intended probe implantation site. A 21 gauge stainless steel guide cannula was then stereotaxically placed into the hole and onto the surface of the cortex overlying either the anterolateral striatum (1.2 mm anterior to bregnia and $3.2 \mathrm{~mm}$ lateral to the midline suture), nucleus accumbens $(+2.0$ $\mathrm{mm} \mathrm{AP}, \pm 1.6 \mathrm{~mm} \mathrm{LAT})$ or medial prefrontal cortex $(+3.2 \mathrm{~mm} \mathrm{AP}$, $\pm 0.7 \mathrm{~mm} \mathrm{LAl}$ ) (Paxinos and Watson, 1982). The guide cannula with a wire obturator was fixed to the skull with cranioplastic cement and three set screws. The vertical placement of the microdialysis probe at the tip of the membrane was $5.0 \mathrm{~mm}$ (caudate) $9.0 \mathrm{~mm}$ (nucleus accumbens), or $5.0 \mathrm{~mm}$ (medial prefrontal cortex) below the cortical sur- face (Paxinos and Watson, 1982). At the time of the dialysis experiments and $3 \mathrm{~d}$ after surgery, all animals returned to their preoperative body weights.

Microdialysis probes. A concentric-shaped dialysis probe was constructed as previously described (Yamamoto and Pehek, 1990; Yamamoto and Davy, 1992). The exposed portion of the membrane (SpectraPor/cellulose, $6000 \mathrm{MW}$ cutoff) was $4.0 \mathrm{~mm}$ (caudatc), $1.5 \mathrm{~mm}$ (nucleus accumbens), or $4.5 \mathrm{~mm}$ (medial prefrontal cortex). The dead volume of each probe was determined before each experiment to coordinate precisely the onset and termination of the $80 \mathrm{~mm} \mathrm{~K}^{+}$infusion with the sample collection. The relative recoveries of the probes for dopamine at $23^{\circ} \mathrm{C}$ were $10 \%, 12 \%$, and $16 \%$ for those probes placed in nucleus accumbens, caudate, and medial prefrontal cortex, respectively. Throughout these studies, variability in relative recoveries between probes of a specified membrane length (e.g., $4.5 \mathrm{~mm}$ ) varied by less than $10 \%$. Due to this consistency between probes designated for a specified brain region, all data are expressed in absolute concentrations and were not corrected for relative recovery.

Microdialysis perfusion. Perfusion flow was controlled by a multisyringe pump (Harvard Instruments, South Natick, MA) at $2.0 \mu \mathrm{l} / \mathrm{min}$. A low dead volume liquid switch (Valco Instrument Co., Houston, TX) was positioned in line between the perfusion pump and a liquid swivel (Instech, Plymouth Meeting, PA). A Teflon tether was used to connect the swivel to the animal and served as a protective covering for the infusion tubing. The low-dead-volume liquid switch permitted the discrete transition to a perfusion medium containing $80 \mathrm{~mm} \mathrm{~K}^{+}$without an interruption in flow rate and no disturbance to the animal. The KrebsRinger medium contained $122 \mathrm{~mm} \mathrm{NaCl}, 3.0 \mathrm{~mm} \mathrm{KCl}, 1.2 \mathrm{~mm} \mathrm{MgSO}_{4}$, $0.4 \mathrm{mM} \mathrm{KH}_{2} \mathrm{PO}_{4}$, and $1.2 \mathrm{mM} \mathrm{CaCl}_{2}, \mathrm{pH}$ 7.40. When a high $\mathrm{K}^{+}$buffer $(80 \mathrm{~mm})$ was used, an equivalent concentration of $\mathrm{NaCl}$ was withheld from the medium to maintain equal molarity.

Dialysis probes were inserted on the day of the dialysis experiment. All dialysis studies were conducted $24 \mathrm{hr}$ after the last drug administration. Perfusion was initiated $3 \mathrm{hr}$ prior to the collection of baseline samples. Dialysate samples were then collected every $30 \mathrm{~min}$ until a $1.5 \mathrm{hr}$ stable baseline was obtained. The perfusion medium was then switched to the Krebs-Ringer medium containing $80 \mathrm{~mm} \mathrm{~K}+$ for $30 \mathrm{~min}$ and subsequently switched back to the normal medium for $1.5 \mathrm{hr}$.

At the end of each experiment, all probe placements were verified from frozen $40-\mu \mathrm{m}$-thick coronal sections.

Biochemical measurements. Dialysate samples were divided and assayed separately for dopamine or glutamate by HPLC with electrochemical detection according to our previously published methods (Donzanti and Yamamoto, 1988a,b). Separation of dopamine from metabolites was achieved with a $3 \mu \mathrm{m} \mathrm{C18}$ column $(100 \mathrm{~mm} \times 2.0 \mathrm{~mm})$ (Phenomenex) and a mobile phase consisting of $32 \mathrm{~mm}$ citric acid, 54.3 mM sodium acetate, $0.074 \mathrm{~mm} \mathrm{Na}_{2}$ EDTA, $0.215 \mathrm{~mm}$ octyl sodium sulfate, and $3.0 \%$ methanol (pH 4.2). Flow rate was $0.40 \mathrm{ml} / \mathrm{min}$. Detection was with a Princeton Applied Research Instrument model 400 Electrochemical Detector and a glassy carbon electrode maintained at a potential of $0.6 \mathrm{~V}$.

A $20 \mu 1$ aliquot of each dialysate sample was assayed for amino acids by precolumn derivatization with $o$-phthaldialdehyde. The derivatization reagent was prepared by dissolving $27 \mathrm{mg}$ of $o$-phthaldialdehyde in $1 \mathrm{ml}$ of $100 \%$ methanol, $9 \mathrm{ml}$ of $0.1 \mathrm{M}$ sodium tetraborate $(\mathrm{pH} 9.4)$, and $10 \mu \mathrm{l}$ of $\beta$-mercaptoethanol. This stock solution was then diluted $1: 3$ with the $0.1 \mathrm{M}$ sodium tetraborate. A $10 \mu \mathrm{l}$ aliquot of the reagent solution was then added to the $20 \mu \mathrm{l}$ dialysate sample. Derivatization was allowed to proceed for $2.0 \mathrm{~min}$ before injection onto the HPLC column. Glutamate was separated from other amino acids on a $3 \mu \mathrm{m}$ $\mathrm{C} 18$ reversed-phase column $(100 \times 4.2 \mathrm{~mm})$ (Phenomenex) and eluted with a 0.1 M sodium phosphate buffer ( $\mathrm{pH} 6.4$ ) containing $25 \%$ methanol and $50 \mathrm{mg} /$ liter of $\mathrm{Na}_{2}$ EDTA. Detection was at a glassy carbon elcctrode maintained at $+0.7 \mathrm{~V}$ by an LC4B amperometric detector (Bioanalytical Systems, Inc.). Flow rate was $1.0 \mathrm{ml} / \mathrm{min}$.

Data analysis. The data were expressed in absolute concentrations (absolute recoveries) as pg or $\mathrm{ng} / 20 \mu \mathrm{l}$ and analyzed by a multifactor analysis of variance with repeated measures followed by post hoc Scheffe tests for multiple comparisons. Only data from animals with accurate probe placements as determined by postmortem histological analysis were included in the data analysis.

\section{Results}

Basal concentrations of dopamine and glutamate in the caudate, nucleus accumbens, and medial prefrontal cortex after chronic 

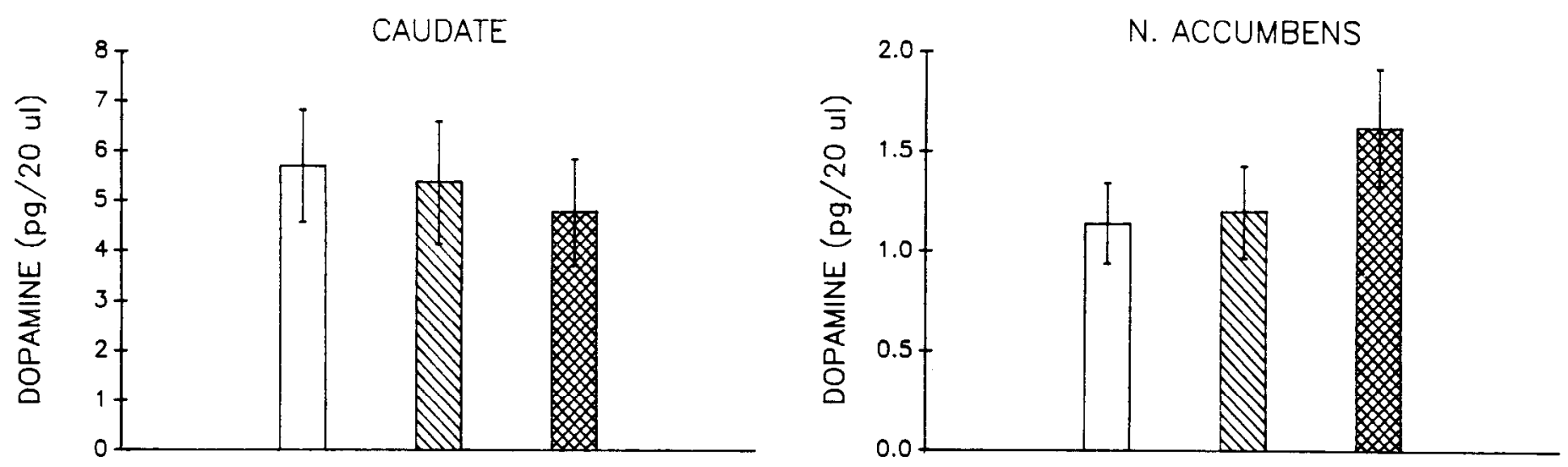

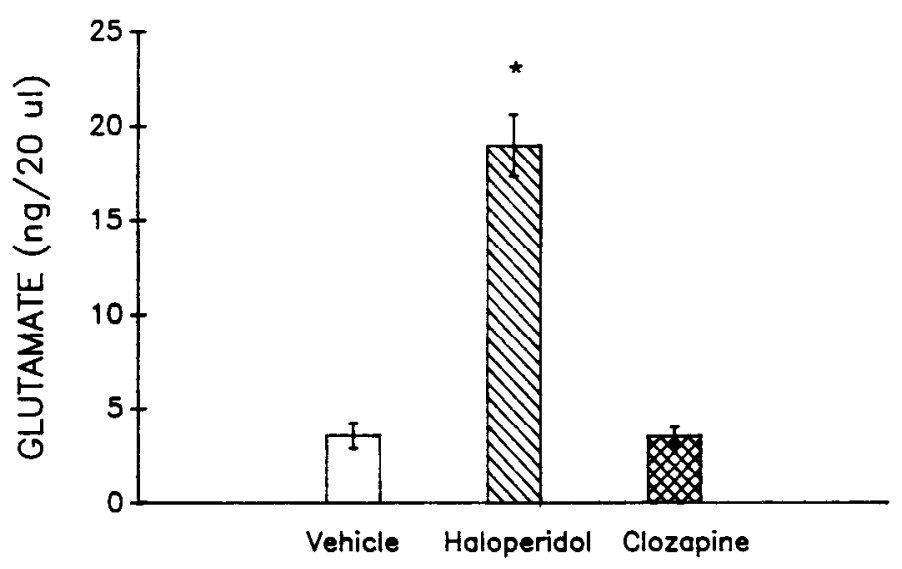

Figure 1. Basal dopamine and glutamate concentrations in the caudate after chronic vehicle, haloperidol, or clozapine administration. Vertical bars are the mean \pm SEM of five to seven rats/group during a $1.5 \mathrm{hr}$ baseline period. *, Significantly different $(p<0.01)$ from vehicle and clozapine groups.

treatment with vehicle, haloperidol, or clozapine are illustrated in Figures 1-3. Dopamine concentrations following chronic clozapine were significantly elevated in the cortex $(74 \%)$ compared to vehicle controls $(p<0.05)$ (Fig. 3). No other changes in basal dopamine levels were found in the caudate or nucleus accumbens after haloperidol or clozapine treatment.

Basal extracellular concentrations of glutamate were significantly increased by haloperidol in both the caudate (Fig. 1) and nucleus accumbens (Fig. 2); however, the magnitude of increase in caudate $(500 \%)$ was much greater than in the accumbens $(75 \%)(p<0.05)$. No changes in glutamate concentrations were noted in the medial prefrontal cortex (Fig. 3).

To investigate whether a single injection of haloperidol produces increases in basal caudate glutamate concentrations, a separate group of rats were pretreated with either one injection of haloperidol $(0.5 \mathrm{mg} / \mathrm{kg}$, i.p.) or tartaric acid vehicle $24 \mathrm{hr}$ prior to the dialysis perfusion. Basal concentrations of glutamate were not different between controls $(3.84 \pm 0.41 \mathrm{ng} / 20 \mu \mathrm{l})$ and haloperidol-pretreated animals $(3.62 \pm 0.38 \mathrm{ng} / 20 \mu \mathrm{l}) . \mathrm{K}^{+}$stimulation increased glutamate efflux equally in both groups (11.6 \pm 1.6 and $10.4 \pm 1.7 \mathrm{ng} / 20 \mu \mathrm{l}$ in the vehicle- and haloperidoltreated animals, respectively).

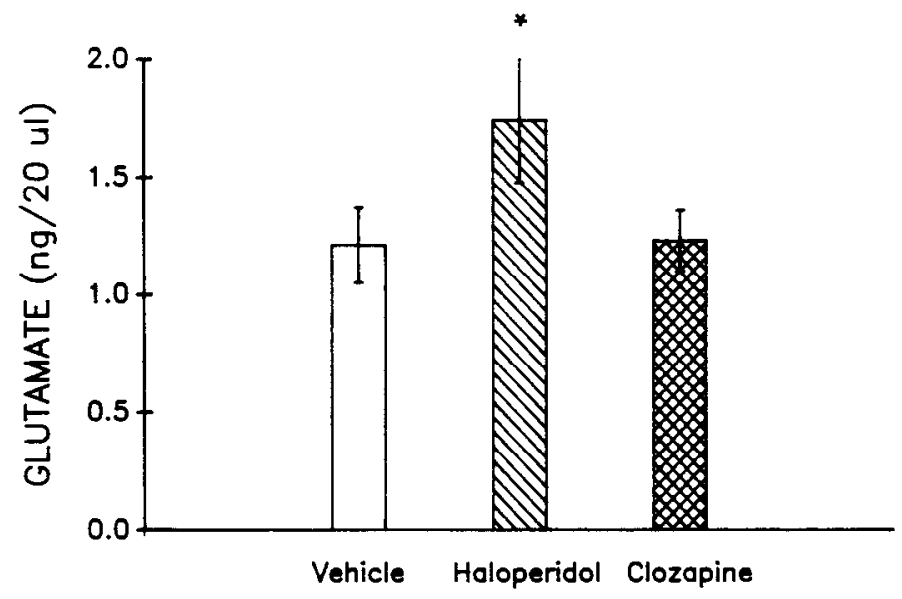

Figure 2. Basal dopamine and glutamate concentrations in the nucleus accumbens after chronic vehicle, haloperidol, or clozapine administration. Vertical bars are the mean \pm SEM of five to seven rats/group during a 1.5 hr baseline period. *, Signiticantly different $(p<0.05)$ from vehicle and haloperidol groups.

Perfusion for 30 min with $80 \mathrm{~mm} \mathrm{~K}^{+}$increased extracellular concentrations of dopamine and glutamate in all three brain regions but the relative magnitude of increase differed for the two compounds. This was also dependent on the brain region examined. $\mathrm{K}^{+}$-stimulated dopamine efflux increased basal concentrations by 28 -fold in caudate and 23 -fold in nucleus accumbens. In contrast, extracellular dopamine concentrations in the medial prefrontal cortcx increased by only 7.4 -fold. The relative magnitude of stimulated glutamate efflux was significantly less than dopamine $(p<0.05)$, but the relative increase in gluta mate was similar across brain regions. This varied from 3 -fold for caudate to 2- and 2.7-fold for nucleus accumbens and medial prefrontal cortex, respectively.

The effects of depolarization-induced dopamine release in the three brain areas following chronic treatment with either vehicle, haloperidol, or clozapine are illustrated in Figures 4-6. Stimulated dopamine efflux in all three regions was reduced by haloperidol treatment. Dopamine release was decreased by $77 \%$ in caudate (Fig. 4), 53\% in nucleus accumbens (Fig. 5), and 36\% in medial prefrontal cortex (Fig. 6) after chronic haloperidol. No changes in the absolute or relative magnitude of stimulated 

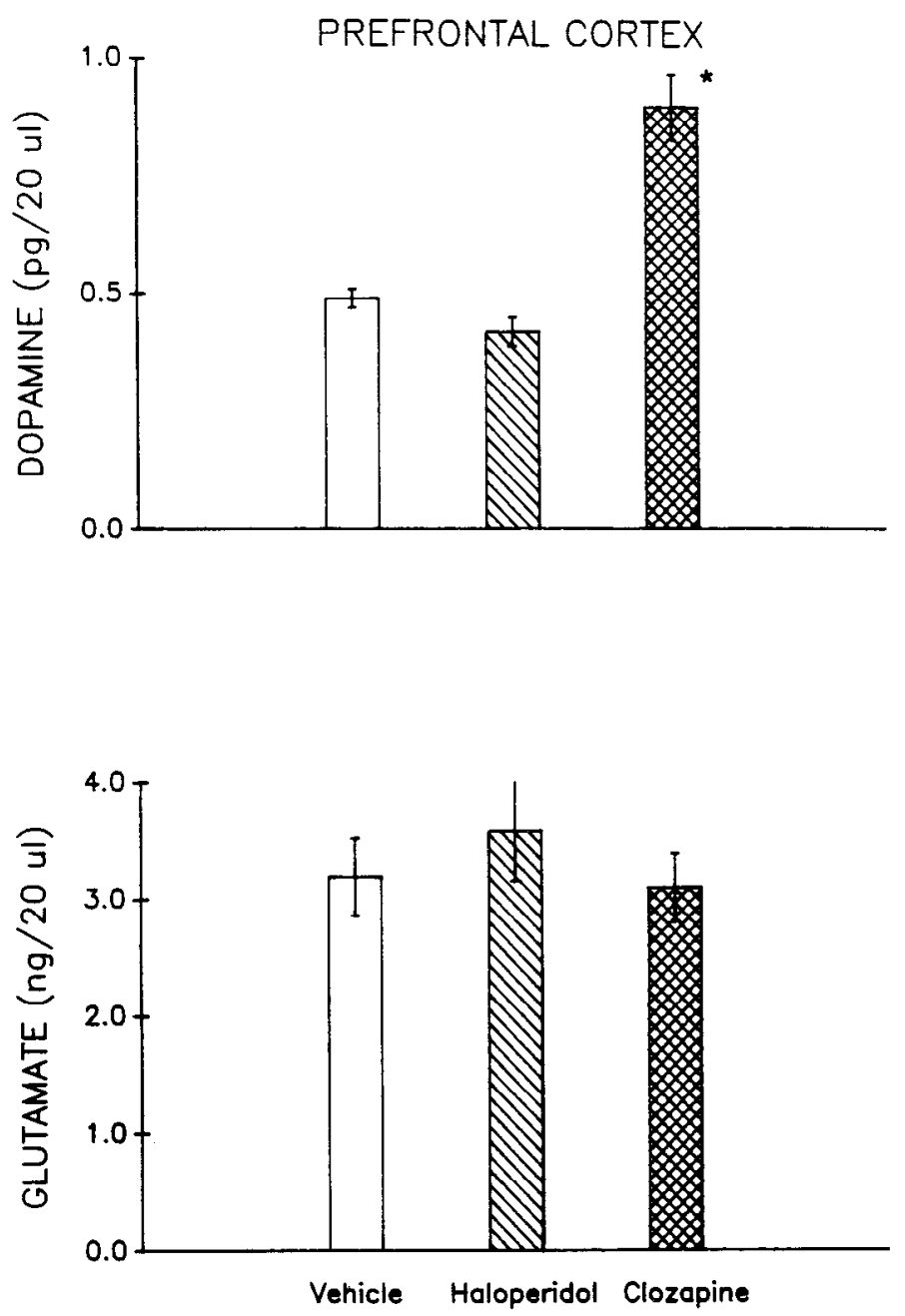

Figure 3. Basal dopamine and glutamate concentrations in the medial prefrontal cortex after chronic vehicle, haloperidol, or clozapine administration. Vertical bars are the mean \pm SEM of five to seven rats/ group during a $1.5 \mathrm{hr}$ baseline period. ${ }^{*}$, Significantly different $(p<$ 0.01 ) from vehicle and haloperidol groups.

dopamine efflux were observed within any of the brain regions examined following clozapine treatment.

In separate experiments, tetrodotoxin (TTX) $(10 \mu \mathrm{M})$ in a calcium-free perfusion medium was used to examine the neuronal contribution to the overall glutamate concentrations of the dialysate samples. Perfusion with a calcium-free medium containing TTX over a $2 \mathrm{hr}$ period did not significantly decrease basal glutamate concentrations but did attenuate the $\mathrm{K}^{+}$-stimulated glutamate efflux by $68 \pm 7 \%$ in each of the three brain regions.

Stimulated glutamate efflux in the caudate, nucleus accumbens, and cortex was also selectively affected by chronic antipsychotic drug treatment (Figs. 7-9). There was an enhanced increase in extracellular glutamate in the nucleus accumbens following chronic clozapine treatment (Fig. 8) as well as in the caudate of haloperidol-treated animals (Fig. 7). Although the absolute concentrations of glutamate during the $80 \mathrm{~mm} \mathrm{~K}{ }^{+}$perfusion in the caudate were significantly higher following chronic haloperidol compared to the other groups, the relative increase from basal values was not different between any of the drug conditions. Therefore, the only significant differences noted in

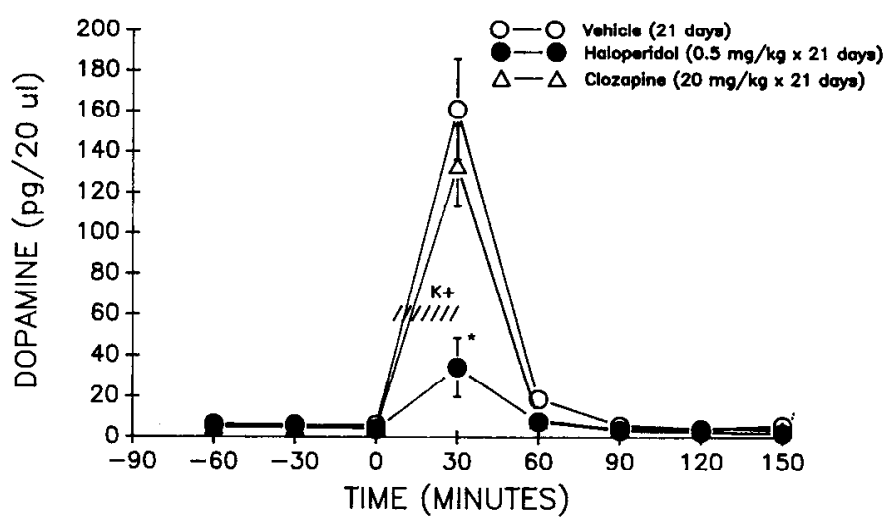

Figure 4. The cffect of chronic drug treatment on $\mathrm{K}^{+}$-stimulated dopamine efflux in the caudate. The diagonal lines represent the period of $80 \mathrm{~mm} \mathrm{~K}^{+}$perfusion. *, Significantly different from vehicle- and clozapine-treated groups $(p<0.01)$. Values are mean \pm SEM of five to seven rats.

the relative increases in stimulated glutamate efflux between groups occurred with comparison of clozapine to the control group for the nucleus accumbens.

\section{Discussion}

Chronic treatment with haloperidol or clozapine produced brain region-dependent effects on both basal and depolarization-induced glutamate and dopamine efflux measured by in vivo microdialysis. Chronic treatment with haloperidol selectively increased basal extracellular concentrations of glutamate in the caudate whereas treatment with the atypical antipsychotic drug clozapine increased basal extracellular dopamine concentrations only in the medial prefrontal cortex. In contrast to basal levels, depolarization-induced dopamine efflux was blunted in all three brain regions examined following chronic haloperidol treatment whereas stimulated glutamate efflux was enhanced in the nucleus accumbens after clozapine.

These data are the first evidence of elevated basal extracellular glutamate concentrations in the caudate and nucleus accumbens following chronic haloperidol administration. These results are different from those of Bardgett et al. (1993), who demonstrated that acute but not chronic haloperidol administration resulted in higher tissue content levels of glutamate. Furthermore and

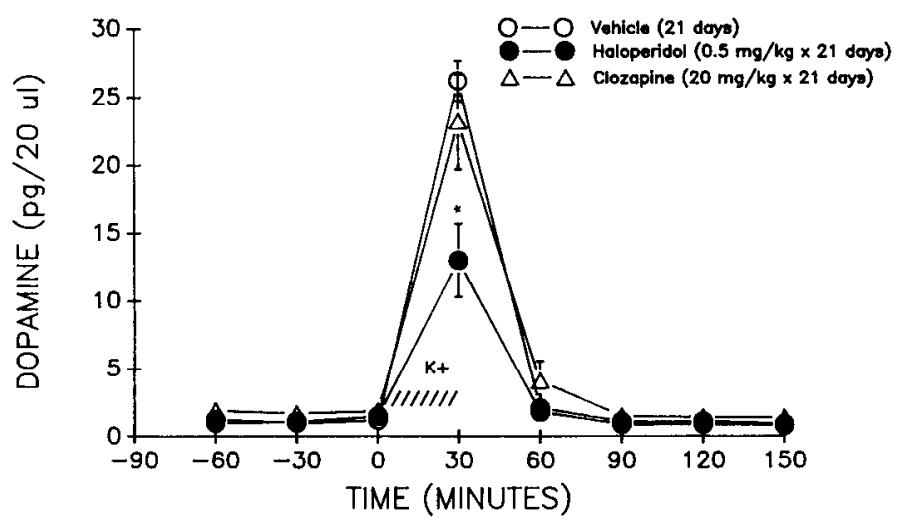

Figure 5. The effect of chronic drug treatment on $\mathrm{K}^{+}$-stimulated dopamine efflux in the nucleus accumbens. The diagonal lines represent the period of $80 \mathrm{~mm} \mathrm{~K}^{+}$perfusion. *, Significantly different from vehicleand clozapine-treated groups $(p<0.05)$. Values are mean \pm SEM of five to seven rats. 


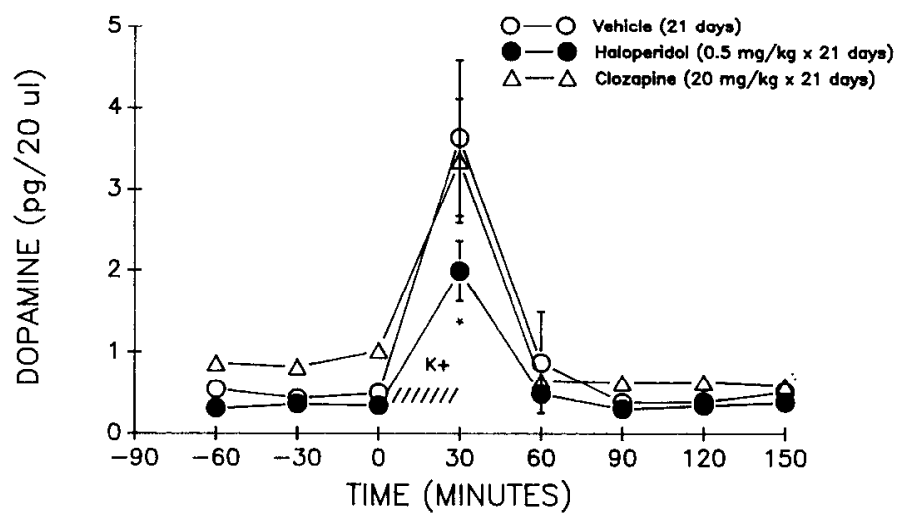

Figure 6. The effect of chronic drug treatment on $\mathrm{K}^{+}$-stimulated dopamine efflux in the medial prefrontal cortex. The diagonal lines represent the period of $80 \mathrm{~mm} \mathrm{~K}{ }^{+}$perfusion. ${ }^{*}$, Significantly different from vehicle- and clozapine-treated groups $(p<0.05)$. Values are mean \pm SEM of five to seven rats.

in contrast to the present study, they reported that both acute and chronic clozapine administration decreased glutamate content in striatum. These differences could be accounted for by the fact that tissue content measurcs of glutamate reflect both intracellular and extracellular pools whereas dialysis perfusates reflect contents of the extracellular synaptic space.

The increase in extracellular glutamate in caudate after chronic haloperidol administration is consistent with a previous report by Moghhadam and Bunney (1993). This effect could be due to a disinhibition of corticostriatal glutamatergic transmission via antagonism of the $\mathrm{D}-2$ receptor produced by the accumulation of haloperidol in the brain. Along these lines, it has been shown that there are D-2 receptors located on corticostriatal nerve terminals (Garau et al., 1978; Schwarcz et al., 1978; Theodorou et al., 1981; Filloux et al., 1989) and that dopamine and D-2 agonists inhibit stimulated glutamate efflux in the striatum (Mitchell and Doggett, 1980; Rowlands and Roberts, 1980; Nieoullon et al., 1982; Kerkerian and Nieoullon, 1988; Maura et al., 1988, 1989; Yamamoto and Davy, 1992). Furthermore, chronic treatment with the D-2 antagonist ( ) sulpiridc incrcases glutamate in cerebrospinal fluid of rats (Kim et al., 1983). In the present study, the fivefold increase in caudate glutamate is particularly striking in light of the lesser increase in the nucleus

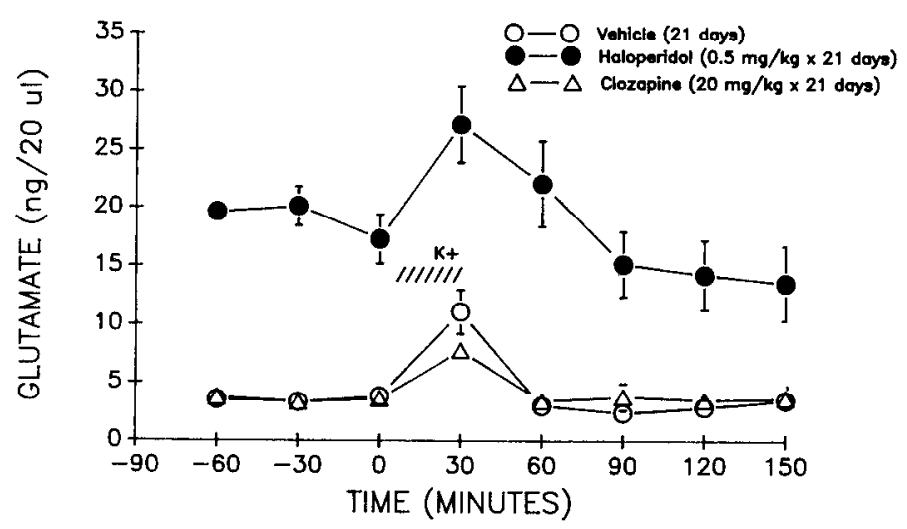

Figure 7. The effect of chronic drug treatment on $\mathrm{K}^{+}$-stimulated glutamate efflux in the caudate. The diagonal lines represent the period of $80 \mathrm{~mm} \mathrm{~K} \mathrm{~K}^{+}$perfusion. Values are mean \pm SEM of five to seven rats.

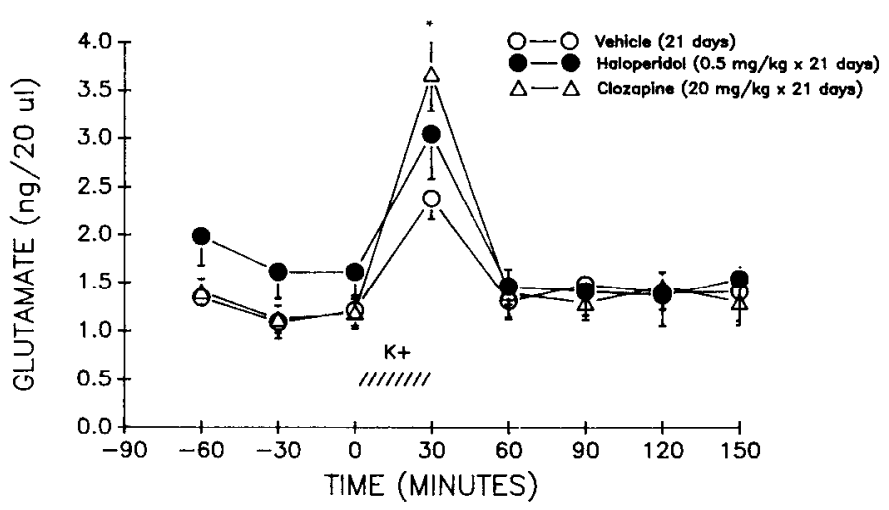

Figure 8. The effect of chronic drug treatment on $\mathrm{K}^{+}$-stimulated glutamate efflux in the nucleus accumbens. The diagonal lines represent the period of $80 \mathrm{~mm} \mathrm{~K} \mathrm{~K}^{+}$perfusion. *, Significantly different from vehicle $(p<0.05)$. Values are mean $\pm \mathrm{SEM}$ of five to seven rats.

accumbens, the lack of effect in cortex, and the absence of any changes following chronic clozapine administration. The elevated concentrations of glutamate in caudate is not due to a persistent effect after the last injection of haloperidol since a single acute administration of haloperidol $24 \mathrm{hr}$ before the dialysis experiment did not increase basal or augment stimulated glutamate efflux. However, a cumulative effect due to pharmacokinetic mechanisms following $21 \mathrm{~d}$ of haloperidol exposure must be taken into consideration.

Our results are consistent with the interpretation of findings reported by Meshul and Casey (1989), who demonstrated a reversible increase in the number of perforated synapses within the dorsolateral caudate $24 \mathrm{hr}$ following chronic haloperidol but not clozapine treatment. The perforated synapse has been hypothesized to be an indicator of increased neuronal activity (Meshul et al., 1989). It also has been speculated that the haloperidol-induced increases in these synapses are due to activation of the excitatory corticostriatal pathway (Meshul and Casey, 1989; Meshul et al., 1992a,b). Support for this interpretation is the ability of the NMDA antagonist MK 801 to reverse the haloperidol-induced increase in perforated synapses (Meshul et al., 1990). It can be posited that the markedly elevated glutamate concentrations in the caudate may be related to the extrapyramidal side effects associated with chronic haloperidol treatment. The present results further highlight and support the hy-

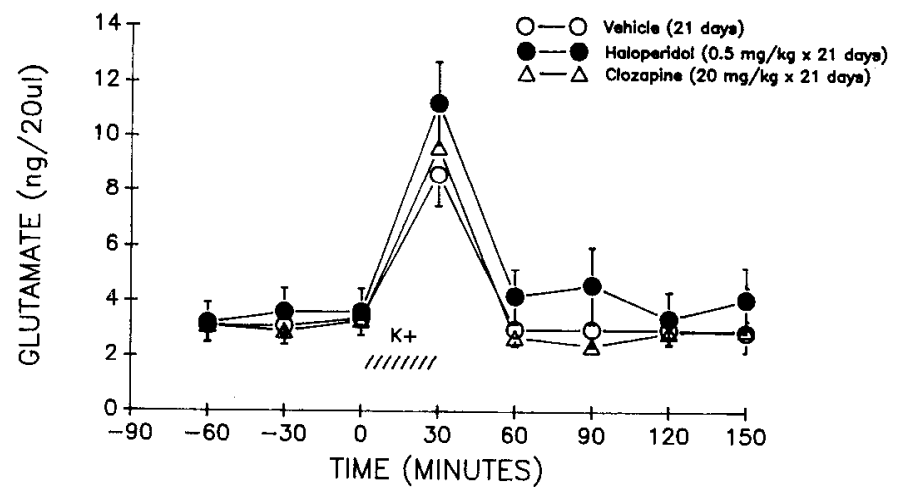

Figure 9. The effect of chronic drug treatment on $\mathrm{K}^{+}$-stimulated glutamate efflux in the medial prefrontal cortex. The diagonal lines represent the period of $80 \mathrm{~mm} \mathrm{~K}^{+}$perfusion. 
pothesis that tardive dyskinesia may be due to a glutamateinduced excitotoxic lesion of the striatal efferent motor pathways (Gunne and Andren, 1993).

An analogous mechanism in the nucleus accumbens cannot easily explain the modest but significant increase in basal glutamate concentrations in this region following chronic haloperidol administration. Although there is no reported evidence of a specific D-2-mediated inhibition of corticoaccumbal glutamate release, the nucleus accumbens does receive excitatory inputs from the cortex (Christie et al., 1987; Groenewegen et al., 1987) that use glutamate and aspartate as transmitters (Fonnum, 1984; Perschak and Cuenod, 1990). Along similar lines, there is a reported interaction between excitatory amino acids and dopamine efflux in the nucleus accumbens (Youngren et al., 1993). Although the mechanism(s) for the enhancement of stimulated glutamate efflux in the nucleus accumbens following chronic clozapine treatment cannot be discerned from the present data, this effect could be due to the ability of clozapine to antagonize the 5- $\mathrm{HT}_{2}$ receptor (Meltzer et al., 1989). There are reports of a serotonergic modulation of dopamine efflux in the nucleus accumbens (Devaud and Hollingsworth, 1991; Devaud et al., 1992), but there is no direct evidence to our knowledge that 5-HT can alter glutamate release in this region. It has been demonstrated in the cercbcllum that $5-\mathrm{HT}$ via the $5-\mathrm{HT}_{2}$ receptor can inhibit stimulated glutamate release, which in turn can be reversed by ketanserin (Maura et al., 1988). Whether a similar mechanism is operative in the nucleus accumbens is not known. Although speculative, it is possible that the $5-\mathrm{HT}_{2}$ antagonist properties of clozapine may disinhibit stimulated glutamate release in the nucleus accumbens. This would be in contrast to the effects of haloperidol on the enhanced basal glutamate efflux in this area, which may be under control by the D-2 receptor. No definitive explanations regarding a serotonergic or dopaminergic involvement in the regional differences in basal and stimulated glutamate efflux can be offered at the present time.

The origin (neuronal vs metabolic) of basal extracellular glutamate concentrations in vehicle-treated rats probably is the metabolic pools, as evidenced by the lack of any change produced by the perfusion of TTX in a calcium-free perfusion medium. However, a majority of the $\mathrm{K}^{+}$-stimulated glutamate efflux appears to be calcium- and impulse-dependent as shown by a significantly attenuated response to $\mathrm{K}^{+}$stimulation during the TTX/calcium-free perfusion. It still remains to be determined whether the increases in basal glutamate concentrations in caudate and the nucleus accumbens produced by chronic haloperidol treatment are from neuronal pools. Regardless of the origin, it is possible that these increases (75-500\%) in extracellular glutamate concentrations can have receptor-mediated effects on striatal neurons. Furthermore, the enhancement of either basal or stimulated glutamate efflux by neuroleptic drugs in limbic regions such as the nucleus accumbens may have therapeutic implications. Several studies have demonstrated decreased glutamate release (Sherman et al., 1991b) and low CSF glutamate levels in the brains of schizophrenics (Kim et al., 1980). These data are consistent with the theory that schizophrenia is a glutamatergic deficiency disorder (Carlsson and Carlsson, 1990; Sherman et al., 1991a). Regardless of the role glutamate plays in schizophrenia, the present results provide evidence that elevated basal and/or enhanced depolarizationinduced increases in extracellular glutamate concentrations in extrapyramidal and limbic nuclei are components of the phar- macological profile of both typical and atypical antipsychotic drugs.

The present results of unaltered basal dopamine concentrations in caudate and nucleus accumbens following chronic treatment with haloperidol agree with some (DeBelleroche and Neal, 1982; Hernandez and Hoebel, 1989; See et al., 1991, 1992; Weidemann and Wightman, 1992) but not other previous findings (Blaha and Lane, 1987; Lane and Blaha, 1987; Zhang et al., 1989; Ichikawa and Meltzer, 1990, 1991, 1992). Electrophysiological studies predict that impulse-mediated dopamine release should be decreased. This is based on the observations that a depolarization inactivation of approximately $80 \%$ of the spontaneously active dopamine cells recorded within the A9 or A 10 regions is produced following chronic haloperidol or clozapine, respectively (Chiodo and Bunney, 1983; White and Wang, 1983a). However, Robinson and Whishaw (1988) have shown that significant decreases in basal dopamine efflux as measured by microdialysis are not apparent until at least an $80 \%$ depletion of dopamine tissue content is produced. It is possible that a $>90 \%$ elimination or inactivation of dopamine neurons is required to reveal marginally significant decreases in the extracellular dopamine concentrations as measured by microdialysis within terminal regions. Furthermore, it has been demonstrated that release from terminals produced by acute or chronic antipsychotic treatment may be dissociated from changes in dopamine neuron firing (Westerink and deVries, 1989; Grace, 1991). Thus, it is not surprising that results vary with regard to the effects of chronic antipsychotic treatment on basal dopamine efflux in forebrain dopamine regions.

The underlying mechanism for the attenuation of stimulated dopamine release in the medial prefrontal cortex by chronic haloperidol is not known. These results are inconsistent with the findings that following chronic haloperidol administration, tolerance does not develop to the increases in dopamine synthesis and metabolism observed after a haloperidol challenge (Bannon et al., 1982). However, the development of tolerance is dependent on the dose and duration of haloperidol administration (Scatton, 1977). The present results suggest that haloperidol produces a decrease in dopaminergic function in the cortex. Since a hypofunction of dopaminergic input to the prefrontal cortex may be associated with the negative aspects of schizophrenia (e.g., anhedonia, social withdrawal; Mackay, 1990), this effect of haloperidol may contribute to its lack of efficacy in alleviating these symptoms.

The elevated basal concentrations of dopamine in the cortex after chronic clozapine treatment differs from the lack of change reported by Chen et al. (1992). The methodology was very similar to the present study with the exception that they used a high $\mathrm{CaCl}_{2}$ concentration in the perfusion medium (3.37 mM). The concentration used in the present study $(1.2 \mathrm{~mm})$ is within the physiological range of striatal extracellular fluid (Moghaddam and Bunney, 1989). It is possible that mesocortical dopamine neurons are particularly sensitive to high $\mathrm{Ca}^{2+}$ concentrations and could have masked subtle differences in basal dopamine efflux. This explanation is supported by the well-established finding that mesocortical dopamine neurons have a higher turnover rate and a higher rate of impulse-mediated and thus $\mathrm{Ca}^{2+}$ dependent activity (Bannon et al., 1981; Bannon and Roth, 1983). Nevertheless, the selectively elevated dopamine concentrations in the cortex by chronic clozapine is similar to previous findings following acute administration (Moghaddam and Bunney, 1990) and may be partially responsible for the efficacy of 
this drug in treating the negative symptoms of schizophrenia (Meltzer, 1989).

One approach that can maximize the probability of detecting region-dependent differences in impulse-mediated dopamine efflux as a function of antipsychotic drug treatment is to examine depolarization-induced dopamine release. As Figures 4-6 illustrate, chronic haloperidol significantly attenuated depolarization-induced dopamine release in all three brain regions whereas clozapine was without effect. These release data are consistent with previous electrophysiological studies and support the hypothesis that chronic haloperidol reduces depolarization-dependent dopaminergic activity (Chiodo and Bunney, 1983, 1985; White and Wang, 1983a,b; Grace and Bunney, 1986). In addition, the lack of any changes in basal or depolarization-induced dopamine efflux in any of the subcortical regions examined following chronic clozapine further highlight the nondopaminergic and perhaps glutamatergic (Fig. 8) or serotonergic (Meltzer et al., 1989) activity of this drug.

In conclusion, this study demonstrates that both basal and local depolarization-induced dopamine as well as glutamate efflux in dopamine terminal fields are altered in a region-dependent manner by chronic antipsychotic drug treatment. This paradigm also appears to differentiate the neurochemical effects of chronic haloperidol and clozapine administration. The attenuation of stimulated dopamine release and the markedly elevated basal levels of glutamate in caudate may contribute to the side-effect liability of haloperidol. In contrast, the enhancement of stimulated glutamate release by clozapine and the moderately elevated basal concentrations of glutamate after haloperidol in the nucleus accumbens may be partly responsible for the antipsychotic effects of these drugs.

\section{References}

Bannon MJ, Roth RH (1983) Pharmacology of mesocortical dopamine neurons. Pharmacol Rev 35:53-68.

Bannon MJ, Bunney EB, Roth RH (1981) Mesocortical dopamine neurons: rapid transmitter turnover compared to other brain catecholamine systems. Brain Res 218:376-382.

Bardgett ME, Wrona CT, Newcomer JW, Csernansky JG (1993) Subcortical excitatory amino acid levels after acute and chronic administration of typical and atypical neuroleptics. Eur J Pharmacol 230: 245-250.

Blaha CD, Lane RF (1987) Chronic treatment with classical and atypical antipsychotic drugs differentially decreases dopamine release in striatum and nucleus accumbens in vivo. Neurosci Lett 78:199-204.

Carlsson M, Carlsson A (1990) Interactions between glutamatergic and monoaminergic systems within the basal ganglia-implications for schizophrenia and Parkinson's disease. Trends Neurosci 13:272276.

Chai B, Meltzer HY (1992) The effect of chronic clozapine on basal dopamine release and apomorphine-induced DA release in the striatum and nucleus accumbens as measured by in vivo microdialysis. Neurosci Lett 136:47-50.

Chen J, Paredes W, Gardner EL (1991a) Chronic treatment with clozapine selectively decreases basal dopamine release in nucleus accumbens but not in caudate-putamen as measured by in vivo brain microdialysis: further evidence for depolarization block. Neurosci Lett 122:127-131.

Chen J, van Pragg HM, Gardner EL (1991b) Activation of 5-HT3 receptor by $l$-phenylbiguanide increases dopamine release in the rat nucleus accumbens. Brain Res 543:354-357.

Chen J, Ruan D, Paredes W, Gardner EL (1992) Effects of acute and chronic clozapine on dopaminergic function in medial prefrontal cortex of awake, freely moving rats. Brain Res 571:235-241.

Chiodo LA, Bunney BS (1983) Typical and atypical neuroleptics: differential effects of chronic administration on the activity of $A 9$ and A10 midbrain dopaminergic neurons. J Neurosci 3:1607-1619.

Chiodo LA, Bunney BS (1985) Possible mechanism by which repeated clozapine administration differentially affects the activity of two subpopulations of midbrain dopamine neurons. J Neurosci 5:2539-2544.

Christie MJ, Summers RJ, Stephenson JA, Cook CJ, Beart PM (1987) Excitatory amino acid projection to the nucleus accumbens septi in the rat: a retrograde transport study utilizing $D-\left[{ }^{3} \mathrm{H}\right]$ aspartate and $\left[{ }^{3} \mathrm{H}\right]$ GABA. Neuroscience 22:425-439.

Creese I, Burt DR, Snyder SH (1976) Dopamine receptor binding predicts clinical and pharmacological potencies of antischizophrenic drugs. Science 192:481-483.

Daly DA, Moghaddam B (1993) Actions of clozapine and haloperidol on extracellular levels of excitatory amino acids in the prefrontal cortex and striatum of conscious rats. Neurosci Lett 152:61 64 .

De Belleroche JS, Neal MJ (1982) The contrasting effects of neuroleptic on transmitter release from the nucleus accumbens and corpus striatum. Neurophamiacology 21:529-537.

Devaud LL, Hollingsworth EB (1991) Effect of the $5 \mathrm{HT}_{2}$ receptor antagonist, ritanserin, on biogenic amines in the rat nucleus accumbens. Eur J Pharmacol 192:427-429.

Devaud LL, Hollingsworth EB, Cooper BR (1992) Alterations in extracellular and tissue levels of biogenic amines in rat brain induced by the serotonin $_{2}$ receptor antagonist, ritanserin. J Neurochem 59: $1459-1466$.

Donzanti BA, Yamamoto BK (1988a) An improved and rapid HPIC.EC method for the isocratic separation of amino acid neurotransmitters from brain tissue and microdialysis perfusates. Life Sci 43: 913-922.

Donzanti BA, Yamamoto BK (1988b) A rapid and simple HPLC microassay for biogenic amines in discrete brain regions. Pharmacol Biochem Behav 30:795-799.

Filloux F, Liu TJ, Hsu CY, Hunt MA, Wamsley JK (1988) Selective cortical infarction reduces [ $\left.{ }^{3} \mathrm{H}\right]$ sulpiride binding in rat caudate-putamen: autoradiographic evidence for presynaptic $\mathrm{D}_{2}$ receptors on corticostriate terminals. Synapse 2:521-531.

Fonnum F (1984) Glutamate: a neurotransmitter in mammalian brain. J Neurochem 42:1-11.

Garau L, Govoni S, Stefanini E, Trabucchi M, Spano PF (1978) Dopamine receptors: pharmacological and anatomical evidences indicated that two distinct populations are present in rat striatum. Life Sci 23:1745-1750.

Grace AA (1991) Phasic versus tonic dopamine release and the modulation of dopamine system responsivity: a hypothesis for the etiology of schizophrenia. Neuroscience 41:1-24.

Grace AA, Bunney BS (1986) Induction of depolarization block in midbrain dopamine neurons by repeated administration of haloperidol: analysis using in vivo intracellular recording. J Pharmacol Exp Ther 238:1092-1100.

Groenewegen HJ, Vermeulen-Van der Zee E, Te Kortschot A, Witter MP (1987) Organization of the projections from the subiculum to the ventral striatum in the rat. A study using anterograde transport of Phaseolus vulgaris leucoagglutinin. Neuroscience 9:701-719.

Gunne LM, Andren PE (1993) An animal model for coexisting tardive dyskinesia and tardive parkinsonism: a glutamate hypothesis for tardive dyskinesia. Clin Neuropharmacol 16:90-95.

Hernandez L, Hoebel BG (1989) Haloperidol given chronically decreases basal dopamine in the prefrontal cortex more than the striatum or nucleus accumbens as simultaneously measured by microdialysis. Brain Res Bull 22:763-769.

Ichikawa J, Meltzer HY (1990a) The effect of chronic clozapine and haloperidol on basal dopamine release and metabolism in rat striatum and nucleus accumbens studied by in vivo microdialysis. Eur J Pharmacol 176:317-374.

Ichikawa J, Meltzer HY (1990b) Apomorphine does not reverse reduced basal dopamine release in rat striatum and nucleus accumbens after chronic haloperidol treatment. Brain Res 507:138-142.

Ichikawa J, Meltzer HY (1991) Differential effects of repeated treatment with haloperidol and clozapine on dopamine release and metabolism in the striatum and the nucleus accumbens. J Pharmacol Exp Ther 256:348-357.

Ichikawa J, Meltzer HY (1992) The effect of chronic atypical antipsychotic drugs and haloperidol on amphetamine-induced dopamine release in vivo. Brain Res 574:98-104.

Jiang LH, Ashby CR, Kasser RJ, Wang RY (1990) The effect of intraventricular administration of the 5 -HT3 receptor agonist 2-methylserotonin on the release of dopamine in the nucleus accumbens: an in vivo chronocoulometric study. Brain Res 513:156-160. 
Kerkerian L, Nieoullon A (1988) Supersensitivity of presynaptic receptors involved in the dopaminergic control of striatal high affinity glutamate uptake after 6-hydroxydopamine lesions of nigrostriatal dopaminergic neurons. Exp Brain Res 69:424-430.

Kim JS, Kornhuber HH, Schmid-Burgk W, Holzmuller B (1980) Low cerebrospinal fluid glutamate in schizophrenic patients and a new hypothesis on schizophrenia. Neurosci Lett 20:379-382.

Kim JS, Claus D, Kornhuber HH (1983) Cerebral glutamate, neuroleptic drugs and schizophrenia: increase in cerebrospinal fluid glutamate levels and decrease in striate body glutamate levels following sulpiride treatment in rats. Eur Neurol 22:367-370.

Lane RF, Blaha CD (1987) Chronic haloperidol decreases dopamine release in striatum and nucleus accumbens in vivo: depolarization block as a possible mechanism of action. Brain Res Bull 18:135-138.

I ane RF, Blaha CD, Rivet IM (1988) Selective inhibition of mesolimbic dopamine release following chronic administration of clozapine: involvement of $\alpha-1$ noradrenergic receptors demonstrated by in vivo voltammetry. Brain Res 460:398-401.

Mackay AVP (1990) Positive and negative schizophrenic symptoms and the role of dopamine. Br J Psychiatry 137:379.

Maura G, Giardi A, Raiteri M (1988a) Release-regulating D-2 dopamine receptors are located on striatal glutamatergic nerve terminals. J Pharmacol Exp Ther 247:680-684.

Maura G, Roccatagliata K, Ulivi M, Raiteri M (1988b) Serotoninglutamate interaction in rat cerebellum: involvement of $5-\mathrm{HT}_{1}$ and 5-HT 2 receptors. Eur J Pharmacol 31-38.

Maura G, Carbone R, Raiteri M (1989) Aspartate-releasing nerve terminals in rat striatum possess D-2 dopamine receptors mediating inhibition of release. J Pharmacol Exp Ther 251:1142-1146.

Meltzer HY (1989) Clinical studies on the mechanism of action of clozapine: the dopamine-serotonin hypothesis of schizophrenia. Psychopharmacology 99:S18-S27.

Meltzer HY, Matsubara S, Lee J-C (1989) Classification of typical and atypical antipsychotic drugs on the basis of dopamine D-1, D-2 and serolonin, $p K_{i}$ values. J Pharmacol Exp Ther 251:238-246.

Meshul CK, Casey DE (1989) Regional, reversible ultrastructural changes in rat brain with chronic neuroleptic treatment. Brain Res 489:338-346.

Meshul CK, Janowsky A, Casey DE, Stallbaumer RK (1990) Haloperidol-induced synaptic changes in rat caudate nucleus are prevented by prior treatment with MK-801 or lesioning of the thalamus. Soc Neurosci Abstr 16:419.

Meshul CK, Janowsky A, Casey DE, Stallbaumer RK, Taylor B (1992a) Coadministration of haloperidol and $\mathrm{SCH}-23390$ prevents the increase in "perforated" synapses due to either drug alone. Neuropsychopharmacology 7:285-293.

Meshul CK, Janowsky A, Casey DE, Stallbaumer RK, Taylor B (1992b) Effect of haloperidol and clozapine on the density of "perforated" synapses in caudate, nucleus accumbens, and medial prefrontal cortex. Psychopharmacology 106:45-52.

Mitchell PR, Doggett NS (1980) Modulation of striatal $\left[{ }^{3} \mathrm{H}\right]$ glutamic acid release by dopaminergic drugs. Life Sci 26:2073-2081.

Moghaddam B, Bunney BS (1989) Ionic composition of microdialysis perfusing solution alters the pharmacological responsiveness and basal outflow of striatal dopamine. J Neurochem 53:652-654.

Moghaddam B, Bunney BS (1990) Acute effects of typical and atypical antipsychotic drugs on the release of dopamine from prefrontal cortex, nucleus accumbens, and striatum of the rat: an in vivo microdialysis study. J Neurochem 54:1755-1760.

Moghaddam B, Bunney BS (1993) Depolarization inactivation of dopamine neurons: terminal release characteristics. Synapse 14:195200.

Nieoullon A, Kerkerian L, Dusticier N (1982) Inhibitory effects of dopamine on high affinity glutamate uptake from rat striatum. Life Sci 30:1165-1172.

Nishikawa T, Takashima M, Toru M (1983) Increased [ $\left.{ }^{3} \mathrm{H}\right]$ kainic acid binding in the prefrontal cortex in schizophrenia. Neurosci Lett 40 : 245-250.

Patterson TA, Schenk JO (1991) Effects of acute and chronic systemic administration of some typical antipsychotic drugs on turnover of dopamine and potassium ion-induced release of dopamine in the striatum of the rat in vivo. Neuropharmacology 30:943-952.

Paxinos G, Watson C (1982) The rat brain in stereotaxic coordinates. New York: Academic.

Pehek EA, Yamamoto BK, Meltzer HY (1991) The effects of clozapine on dopamine, 5-HT, and glutamate release in the rat medial prefrontal cortex. Schizophr Res 4:323.

Perschak H, Cuenod M (1990) In vivo release of endogenous glutamate and aspartate in the rat striatum during stimulation of the cortex. Neuroscience 35:283-287.

Robinson TE, Whishaw IQ (1988) Normalization of extracellular dopamine in striatum following recovery from a partial unilateral 6-OHDA lesion of the substantia nigra: a microdialysis study in freely moving rat. Brain Res 450:209-224.

Rowlands GJ, Roberts PJ (1980) Activation of dopamine receptors inhibits calcium-dependent glutamate release from corticostriatal terminals in vitro. Eur J Pharmacol 62:241-242.

Scatton B (1977) Differential regional development of tolerance to increase in dopamine turnover upon repeated neuroleptic administration. Eur J Pharmacol 46:363-369.

Schwarcz R, Creese I, Coyle JT, Snyder SH (1978) Dopamine receptors localized on cerebral cortical afferents to rat corpus striatum. Nature 271:766-768.

See RE (1991) Striatal dopamine metabolism increases during longterm haloperidol administration in rats but shows tolerance in response to acute challenge with raclopride. Neurosci Lett 129:265268.

See RE, Chapman MA, Murray CE, Aravagiri M (1992) Regional differences in chronic neuroleptic effects on extracellular dopamine activity. Brain Res Bull 29:473-478.

Seeman P, Lee T, Chau-Wong M, Wong K (1976) Antipsychotic drug doses and neuroleptic/dopamine receptors. Nature 261:717-719.

Sherman AD, Davidson AT, Baruah S, Hegwood TS, Waziri R (1991a) Evidence of glutamatergic deficiency in schizophrenia. Neurosci Lett 121:77-80.

Sherman AD, Hegwood TS, Baruah S, Waziri R (199lb) Deficient NMDA-mediated glutamate release from synaptosomes of schizophrenics. Biol Psychiatry 30:1191-1198.

Stockmeier CA, DiCarlo JJ, Zhang Y, Thompson P, Meltzer HY (1993) Characterization of typical and atypical antipsychotic drugs based on in vivo occupancy of serotonin and dopamine $_{2}$ receptors. J Pharmacol Exp Ther 266:1374-1384.

Theodorou A, Reavill C, Jenner P, Marsden CD (1981) Kainic acid lesions of striatum and decortication reduce specific $\left[{ }^{3} \mathrm{H}\right]$ sulpiride binding in rats, so D-2 receptors exist post-synaptically on corticostriate afferents and striatal neurons. J Pharm Pharmacol 33:439444.

Umeda Y, Sumi T (1990) Decrease in the evoked release of endogenous dopamine and dihydroxyphenylacetic acid from rat striatal slices after withdrawal from repeated haloperidol. Eur J Pharmacol 191: $149-155$.

Westerink BHC, deVries JB (1989) On the mechanism of neuroleptic induced increase in striatal dopamine release: brain dialysis provides direct evidence for mediation by autoreceptors localized on nerve terminals. Neurosci Lett 99:197-202.

White FJ, Wang RX (1983a) Comparison of the effects of chronic haloperidol treatment on A-9 and A-10 dopaminergic neurons in the rat. Life Sci 32:983-993.

White FJ, Wang RX (1983b) Differential effects of classical and atypical antipsychotic drugs an A9 and A10 dopamine neurons. Science 221:1054-1057.

Wiedemann DJ, Garris PA, Near JA, Wightman RM (1992) Effect of chronic haloperidol treatment on stimulated synaptic overflow of dopamine in the rat striatum. J Pharmacol Exp Ther 261:574-579.

Yamada S, Yokoo H, Harajiri S, Nishi S (1991) Alterations in dopamine release from striatal slices of rats after chronic treatment with haloperidol. Eur J Pharmacol 192:141-145.

Yamamoto BK, Davy S (1992) Dopaminergic modulation of glutamate release in striatum as measured by microdialysis. J Neurochem 58:1736-1742.

Yamamoto BK, Pehek EA (1990) A neurochemical heterogeneity of the rat striatum as measured by in vivo electrochemistry and microdialysis. Brain Res 506:236-242.

Youngren KD, Daly DA, Moghaddam B (1993) Distinct actions of endogenous excitatory amino acids on the outflow of dopamine in the nucleus accumbens. J Pharmacol Exp Ther 264:289-293.

Zhang W, Tilson H, Stachowiak MK, Hong JS (1989) Repeated haloperidol administration changes basal release of striatal dopamine and subsequent response to haloperidol challenge. Brain Res 484:389392. 